\title{
Perilaku Hidup Bersih dan Sehat (PHBS) pada Anak Sekolah
}

\author{
Endah Nurmahmudah ${ }^{* 1}$, T Puspitasari² ${ }^{2}$ I T Agustin ${ }^{3}$ \\ Universitas Muhammadiyah Tasikmalaya \\ Email: endah@umtas.ac.id
}

\begin{abstract}
ABSTRAK
PHBS merupakan singkatan dari Perilaku Hidup Bersih dan Sehat yaitu sekumpulan perilaku yang dipraktekkan atas dasar kesadaran sebagai upaya agar dirinya sehat dan aktif membantu kesehatan lingkungan di sekitarnya. PHBS pada usia dini sangat baik untuk mendidik dan menanamkan kesadaran akan pentingnya kebersihan sebagai upaya menjaga kesehatan diri dan lingkungan. PKM ini bertujuan untuk memberikan pengetahuan dan pemahaman tentang PHBS kepada anak sekolah dalam hal ini siswa-siswi TK Al-Fadhiilah dan siswa-siswi SDN Cibangunkidul, sehingga siswa-siswi TK Al-Fadhiilah dan SDN Cibangunkidul dapat mempraktekkannya dalam kehidupan sehari-hari. Metode pelaksanaan dilakukan dengan penyuluhan menggunakan in-focus, note book dan beberapa alat peraga.Penyuluhan PHBS pada anak sekolah berjalan lancar, semua peserta baik Siswa TK maupu siswa SD antusias mengikuti kegiatan PKM ini.
\end{abstract}

Kata Kunci: Penyuluhan, PHBS, Anak Sekolah

\begin{abstract}
PHBS stands for clean and healthy living behavior. It is a set of behaviors that are practiced on the basis of awareness in an effort to be healthy and active in helping the healthy of the surrounding environment. PHBS at an early age is very good for educating and instilling awareness of the importance of hygiene as an effort to maintain personal health and the environment. This PKM aims to provide knowledge and understanding of PHBS to students of TK Al-Fadhiilah and the students of SD Cibangunkidul, so that students can practice it in their daily lives. The implementation method was carried out by counseling using in-focus, note-book, and some teaching aids. PHBS counseling for school children went well, all participants were enthusiastic about participating in this PKM activity.
\end{abstract}

Keywords: Counseling, PHBS, School Children

\section{PENDAHULUAN}

\section{Latar belakang}

Semua perilaku manusia sebenarnya pasti punya pengaruh terhadap kesehatan, apapun bentuknya, mulai dari makan, tidur, mandi, berpakaian, olah raga sampai cara belajar, hanya saja diprioritaskan mana perilaku yang berpotensi menimbulkan penyakit. PHBS atau Perilaku Hidup Bersih dan Sehat memang sepertinya mudah dikatakan tapi penerapannya sangat sulit karena membutuhkan kesadaran dan kesungguhan akan pentingnya menjaga kesehatan.

PHBS merupakan salah satu pilar utama dalam Indonesia Sehat dan merupakan salah satu strategi untuk mengurangi beban negara dan 
masyarakat terhadap pembiayaan kesehatan. Kondisi sehat dapat dicapai dengan mengubah perilaku dari yang tidak sehat menjadi perilaku sehat serta menciptakan lingkungan sehat, oleh karena itu kesehatan perlu dijaga, dipelihara dan ditingkatkan oleh setiap anggota rumah tangga serta diperjuangkan oleh semua pihak.

Hidup ber-PHBS berarti mampu menjaga dan meningkatkan serta melindungi kesehatan dirinya dari gangguan penyakit dan lingkungan yang kurang kondusif untuk hidup sehat. Penerapan PHBS di masyarakat merupakan tanggung jawab setiap orang yang juga menjadi tanggung jawab pemerintah kota beserta jajaran sektor terkait untuk memfasilitasi kegiatan PHBS di masyarakat agar dapat dijalankan secara efektif.

Pada usia 6-12 tahun, PHBS dilakukan tidak hanya di lingkungan rumah tapi juga di lingkungan sekolah. PHBS pada usia dini ini baik untuk mendidik dan menanamkan kesadaran akan pentingnya kebersihan sebagai upaya menjaga kesehatan diri dan lingkungan.

Penerapan PHBS di sekolah menurut Sya'roni. RS (2007), antara lain :

1. Menanamkan nilai-nilai untuk ber-PHBS kepada siswa sesuai dengan kurikulum yang berlaku (kurikuler)

2. Menanamkan nilai-niali untuk ber-PHBS kepada siswa yang dilakukan di luar jam pelajaran biasa (ekstrakurikuler)

- Kerja bakti dan lomba kebersihan kelas

- Aktivitas kader kesehatan sekolah/dokter cilik

- Pemeriksaan kualitas air secara sederhana

- Pemeliharaan jamban sekolah

- Pemeriksaan jentik nyamuk di sekolah

- Demo/gerakan cuci tangan dan gosok gigi yang baik dan benar

- Pembudayaan olahraga yang teratur dan terukur

- Pemeriksaan rutin kebersihan : kuku, rambut, telinga, gigi

3. Membimbing hidup bersih dan sehat melalui konseling

Kegiatan penyuluhan dan latihan keterampilan dengan melibatkan peran aktif siswa, guru, orang tua, antara lain melalui penyuluhan kelompok, pemutaran kaset radio atau film, penempatan media poster, penyebaran leaflet dan membuat majalah dinding

4. Pemantauan dan evaluasi.

- Melakukan pemantauan dan evaluasi secara periodik tentang kebijakan yang telah dilaksanakan.

- Minta pendapat pokja PHBS di sekolah dan lakukan kajian terhadap masalah yang ditemukan

- Putuskan apakah perlu penyesuaian terhadap kebijakan

\section{Permasalahan}

Penerapan PHBS di sekolah merupakan kebutuhan mutlak seiring munculnya berbagai penyakit yang sering menyerang anak usia sekolah (6-12 tahun), yang ternyata umumnya rentan dengan PHBS. PHBS di sekolah merupakan sekumpulan perilaku yang dipraktikan peserta didik, guru, dan masyarakat lingkungan sekolah atas dasar keasadaran sebagai hasil pelajaran, sehingga secara mandiri mampu mencegah penyakit, meningkatkan kesehatannya, serta berperan aktif dalam mewujudkan lingkungan sehat.

Dengan mengacu pada latar belakang di atas, maka kehidupan ber-PHBS sangatlah penting di kalangan anak usia sekolah demi untuk meningkatkan kesadaran dan pengetahuan siswa agar dapat mempraktekkan perilaku Hidup Bersih dan Sehat. 


\section{METODE PENELITIAN}

Menyadari bahwa prilaku adalah sesuatu yang rumit, prilaku tidak hanya menyangkut dimensi kultural yang berupa sistem nilai dan norma, melainkan juga dimensi ekonomi yaitu hal-hal yang mendukung prilaku. Maka metode pendekatannya melalui promosi kesehatan berupa penyuluhan gerakan PHBS di sekolah diharapkan dapat melaksanakan strategi yang bersifat paripurna (komprehensif), khususnya dalam menciptakan prilaku baru yaitu ber-PHBS di sekolah.

Beberapa indikator yang dipakai sebagai ukuran untuk menilai PHBS di sekolah yaitu:

a. Mencuci tangan dengan air yang mengalir dan menggunakan sabun

b. Mengkonsumsi jajanan sehat di kantin sekolah

c. Menggunakan jamban yang bersih dan sehat

d. Olahraga yang teratur dan terukur

e. Menimbang berat badan dan mengukur tinggi badan setiap 6 bulan sekali

f. Memelihara kebersihan badan yaitu kuku, rambut dan gigi

g. Membuang sampah pada tempatnya

Kegiatan penyuluhan ini dilakukan oleh dosen sebagai pengusul dan dibantu oleh 2 orang mahasiswa. Mahasiswa membantu menjadi operator, narasumber kedua serta pencatat pemeriksaan. Kegiatan penyuluhan digelar di satu ruangan yang memadai sarana prasarananya yaitu tersedia saluran listrik untuk penggunaan notebook dan in-focus serta mampu menampung peserta. Dan di outdoor untuk beberapa demontrasi.

Sasaran dari program pengabdian masyarakat yang kami lakukan ini adalah siswa-siswi TK Al-Fadhiilah dan siswa-siswi SD Negeri Cibangunkidul yang beralamat di kampung Cibangunkidul Kelurahan Ciherang Kecamatan Cibeureum Kota Tasikmalaya. Mitra PKM dalam hal ini Kepala sekolah TK Al-Fadhiilah dan Kepala sekolah SD Negeri Cibangunkidul telah memberikan kesanggupan untuk memberikan waktu luang anak didiknya dan bersedia memfasilitasi sarana prasarana untuk kelancaran penyuluhan PHBS tersebut.

Kegiatan penyuluhan PHBS :

1. Tahap Persiapan
a. Analisis Situasi
b. Melakukan koordinasi untuk menentukan pelaksanaan pertemuan
c. Menyusun usulan PKM
d. Pengajuan pengusulan PKM

2. Tahap Pelaksanaan

a. Tempat : TK Al-Fadhiilah dan SD Negeri Cibangunkidul

b. Waktu : Agustus 2017

c. Pukul : $08 \mathrm{~s} / \mathrm{d}$ selesai

d. Pelaksana :

1. Dosen Pengusul PKM

2. 2 orang mahasiswa yang berkontribusi

e. Langkah pelaksanaan :

1. Kegiatan :

- Kegiatan pendahuluan : Perkenalan dan penjelasan pelaksanaan PHBS

- Kegiatan inti : Penyampaian materi. tanya jawab, dan praktek langsung/ demonstrasi tentang PHBS

- Kegiatan penutup : penarikan kesimpulan tentang PHBS

2. Metode : Ceramah, in-focus dan tanya jawab

3. Media : notebook, infocus, dan alat peraga. 

f. Evaluasi
1. Pre test
2. Pos test
g. Refleksi

\section{HASIL DAN PEMBAHASAN}

\section{Hasil}

Pelaksanaan kegiatan PHBS bagi anak sekolah ini merujuk pada 4 langkah action research yaitu : perencanaan, tindakan, obsevasi dan evaluasi, serta refleksi. Tahapan tersebut dijelaskan sebagai berikut :

1. Perencanaan

a. Perizinan ke Fakultas Ilmu Kesehatan, Sekolah Dasar Negeri Cibangunkidul dan TK Al-Fadhiilah

b. Sosialisasi program penyuluhan PHBS di SDN Cibangun kidul dan TK AlFadhiilah yang melibatkan siswa, guru dan tim pelaksana

c. Penyusunan program penyuluhan dan pelayanan fasilitas

2. Pelaksanaan

Pelaksanaan dalam kegiatan ini berupa implementasi Program Kegiatan yang dilaksanakan adalah:

a. Edukasi Program PHBS untuk siswa

b. Mendemonstrasikan olahraga yang teratur dan terukur

c. Pengukuran berat dan tinggi badan

d. Memeriksa kebersihan badan yaitu kuku, rambut dan gigi

e. Mendemonstrasikan metode cuci tangan bersih

f. Mendemonstrasikan sikat gigi yang benar

g. Edukasi Mengkonsumsi jajanan sehat di kantin sekolah

h. Edukasi Membuang sampah pada tempatnya

3. Observasi, monitoring dan evaluasi

Observasi dilakukan terhadap proses implementasi kegiatan berdasarkan indikator program PHBS. Instrument yang digunakan untuk observasi dan monitoring berupa check list dan pengisian kolom-kolom berdasarkan kriteria indikator program PHBS.

Berikut adalah kegiatan evaluasi :

Tabel 1 Evaluasi Kegiatan

\begin{tabular}{cccc}
\hline $\mathrm{N}$ & \multirow{2}{*}{ EVALUASI } & \multicolumn{2}{c}{ SASARAN } \\
\cline { 3 - 4 } $\mathrm{O}$ & & \multicolumn{1}{c}{ SISWA } & \multicolumn{1}{c}{ GURU \& STAF } \\
\hline 1 & Pre test & $\begin{array}{l}\text { Dilakukan di } \\
\text { awal program }\end{array}$ & $\begin{array}{l}\text { Dilakukan di awal } \\
\text { program }\end{array}$ \\
& \multirow{2}{*}{ Post test } & $\begin{array}{l}\text { Dilakukan di } \\
\text { akhir program }\end{array}$ & $\begin{array}{l}\text { Dilakukan di akhir } \\
\text { program }\end{array}$ \\
\hline
\end{tabular}

*Pre test dan Post test dilakukan secara lisan saja

4. Refleksi

Refleksi dilakukan terhadap kegiatan yang telah dilaksanakan. Hal ini dilakukan untuk mengetahui kekurangan-kekurangan atau kelebihan-kelebihan terhadap kegiatan yang 
telah dilakukan dalam rangka untuk menetapkan rekomendasi terhadap keberlangsungan atau pengembangan kegiatan berikutnya.

\section{Pembahasan}

Kegiatan penyuluhan PHBS (Perilaku Hidup Bersih dan Sehat) pada anak sekolah dilakukan di dua sekolah yaitu TK Al-Fadhiilah dengan peserta sejumlah 18 siswa berusia 4-6 tahun. Sasaran kedua adalah SD Cibangunkidul dengan peserta seluruh siswa sekolah dasar dari mulai kelas satu sampai dengan kelas enam, dari umur 7 tahun sampai 12 tahun. Kegiatan penyuluhan PHBS berjalan lancar, semua siswa antusias mengikuti kegiatan PKM ini.

Berdasarkan hasil pre test dan pos test, kegiatan PKM ini mampu meningkatkan kesadaran dan pengetahuan siswa agar dapat mempraktekkan perilaku Hidup Bersih dan Sehat.

\section{PENUTUP}

\section{Kesimpulan}

Kegiatan PKM dengan Perilaku Hidup Bersih dan Sehat (PHBS) pada anak sekolah yang dilaksanakan di TK Al-Fadhiilah dan SD Cibangunkidul berjalan dengan lancar. Semua siswa antusias mengikuti kegiatan ini sehingga kegiatan PKM ini telah mampu meningkatkan kesadaran dan pengetahuan siswa agar dapat mempraktekan perilaku Hidup Bersih dan Sehat dalam kehidupan sehari-harinya

\section{Saran}

Berhubungan dengan perilaku maka untuk kegiatan penyuluhan PHBS ini disarankan untuk dilakukan secara continue agar siswa terbiasa hidup bersih dan sehat

\section{DAFTAR PUSTAKA}

Dinkes Surabaya (2009), Buku Saku Pelaksanaan PHBS bagi masyarakat Surabaya, Dinas Kesehatan Surabaya.

Siswanto, Hadi (2009) Pendidikan Kesehatan Anak Usia Dini, Pustaka Rihana : Jakarta

Sya'roni RS (2007), Ilmu Kesehatan Masyarakat, Jakarta : Rineka Cipta

Umar, Zaidina (2007). Perilaku Cucu Tangan Sebelum Makan dan Kecacingan pada Murid SD di Kabupaten Pesisir Selatan Sumatera Barat. Jurnal Kesehatan Masyarakat Nasional Kesehatan Masyarakat 2 (2);250 


\section{Lampiran}

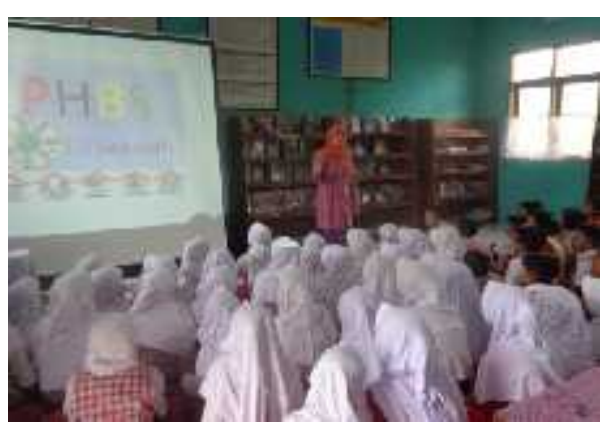

Gambar 1. Edukasi PHBS di SD

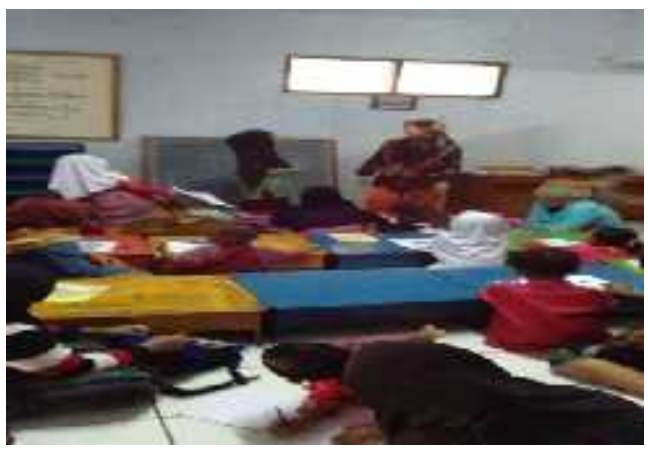

Gambar 3. Edukasi PHBS di TK

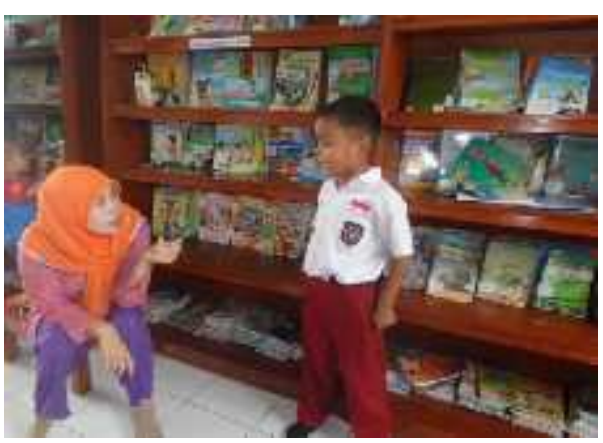

Gambar 5. Pos test

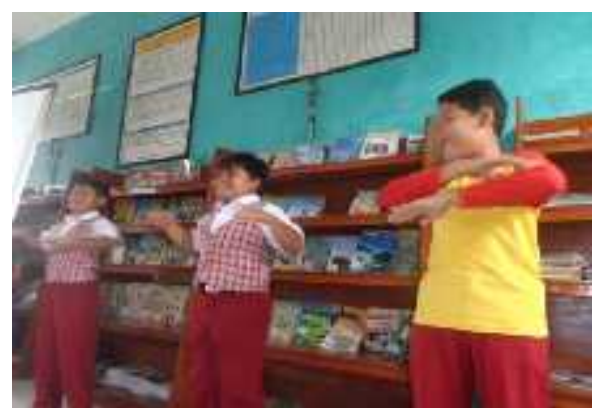

Gambar 7. Pos test gerakan olahraga

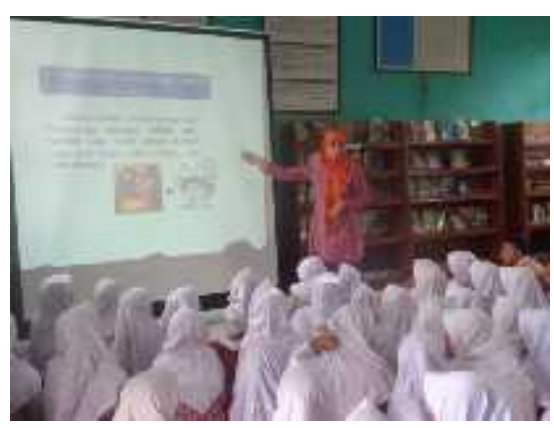

Gambar 2. Edukasi PHBS di SD

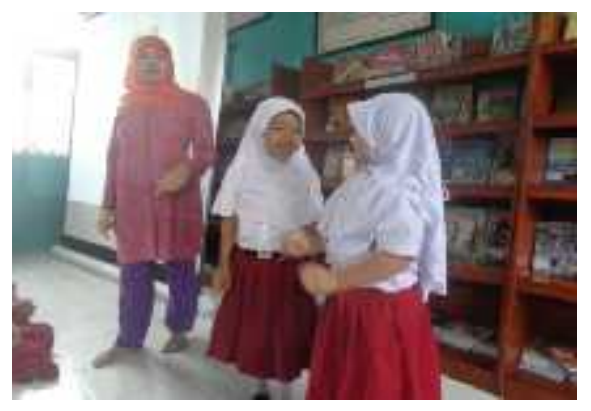

Gambar 4. Pre test

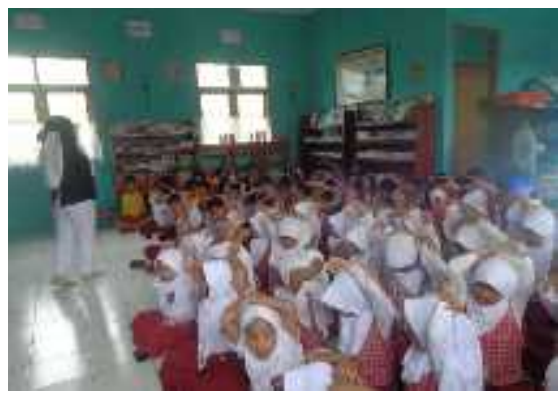

Gambar 6. Demonstrasi olahraga

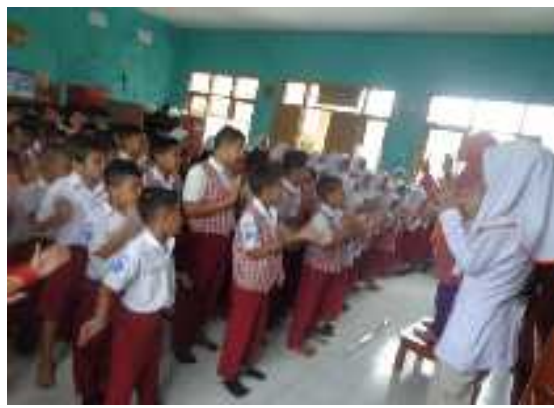

Gambar 8. Demonstrasi 


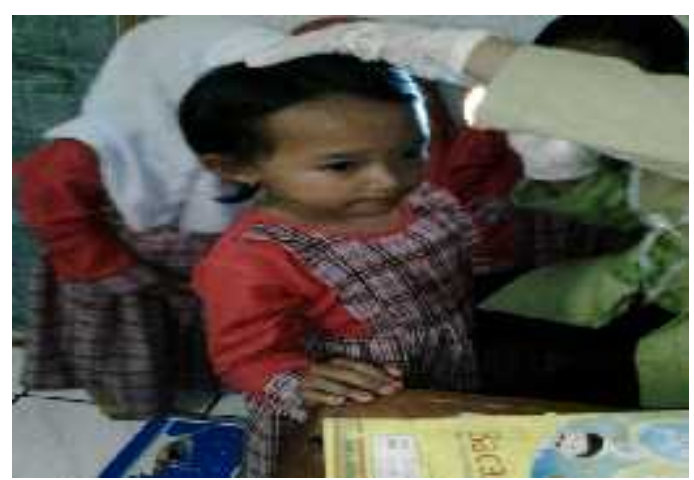

Gambar 9. Pemeriksan kesehatan TK

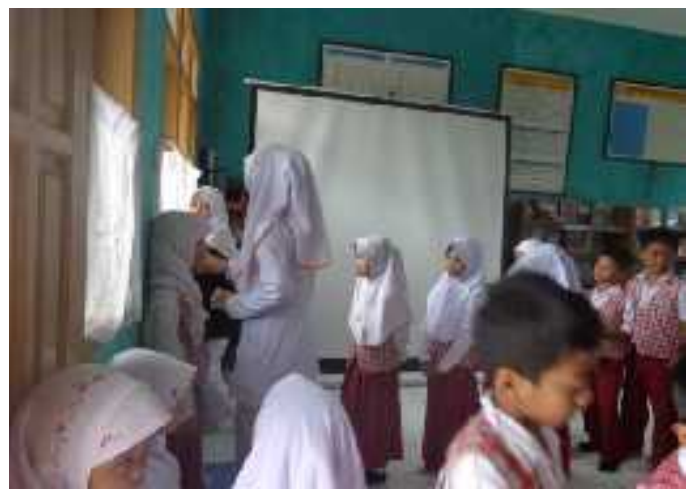

Gambar 11. Pengukuran tinggi badan

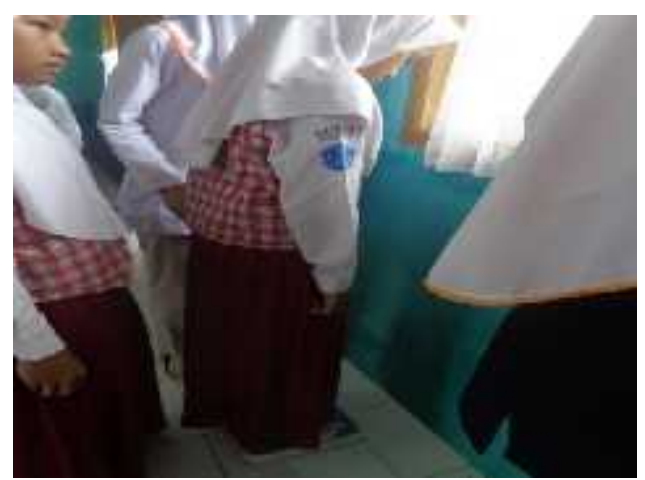

Gambar 10. Pengukuran berat badan SD

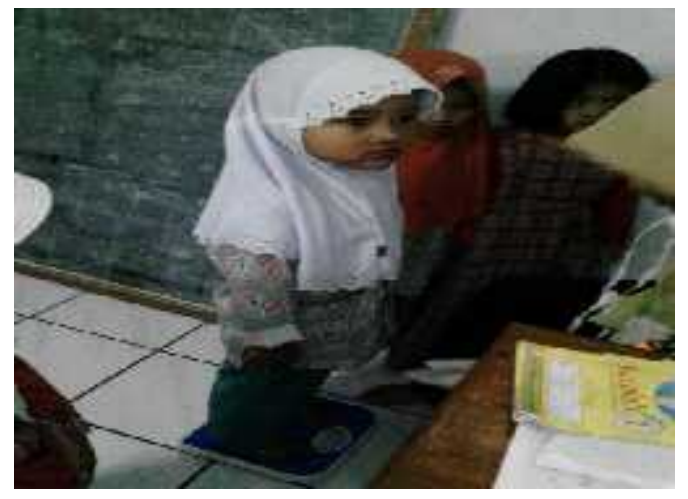

Gambar12. Pengukuran berat badan TK

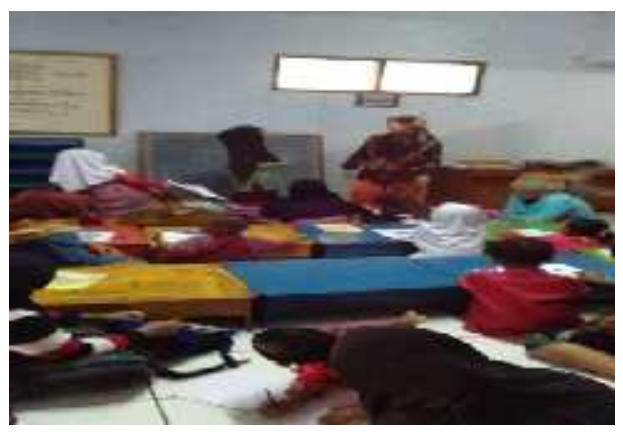

Gambar 13. Edukasi PHBS di TK 